\title{
EDUCAR PARA A DEMOCRACIA
}

\author{
MAURÍCIO MOGILKA \\ Universidade Federal do Paraná \\ mauriciomogilka@ufpr.br
}

\begin{abstract}
RESUMO
Este artigo tem por preocupação central definir e discutir o conceito de educação democrática. Ele desenvolve a discussão baseando-se nos conceitos e reflexões da pedagogia humanista, especialmente no pensamento social de John Dewey. Nesse enfoque interacionista, entende-se a educação como um processo circunscrito socialmente e simultaneamente capaz de modificar estruturas, pela formação de novos tipos de subjetividade e pela articulação com as demais /utas sociais. Nesta direção, o artigo procura mostrar de que maneira a educação democrática aponta para experiências de formação nas quais as crianças podem estruturar a sua subjetividade de forma autônoma, sem o uso da coerção.

DEMOCRATIZAÇÃODAEDUCAÇÃO-DEWEY,JOHN-PEDAGOGAHUMANISTA-PRÁTICA EDUCATNA
\end{abstract}

\section{ABSTRACT}

EDUCATING FOR DEMOCRACY. This article's main concern is to define and discuss the concept of democratic education. This discussion is developed based on the concepts and reflections of humanistic pedagogy, especially the social thinking ofJohn Dewey. In this interactive focus, education is understood as a socially circumscribed process, simultaneously capable of modifying structures by forming new types of subjectivity and by articulating with other social struggles. In this sense, the article attempts to show how democratic education points to formative experiences through which children can autonomously structure their subjectivity, without the use of coercion. DEMOCRATIZATIONOFEDUCATION-DEWEY,JOHN-EDUCATIONAL PRACTICE 
Não creio que as escolas possam ser, literalmente, construtoras da nova ordem social. No entanto, as escolas podem participar, concretamente e não idealmente, da construção da nova ordem socialà medida que se forem aliando com este ou aquele movimento, no seio das forças sociais existentes (...) O desejo de necessidade assume um papel preponderante na determinação da nova ordem social, à medida que os educadores se alinham com os velhos ideais individualistas ou com as novas forças que criamo controle social do podereconômico.

John Dewey

\section{A COMPLEXA RELAÇÃO ENTRE TEORIA E PRÁTICA}

É altamente desejável que a prática (no sentido de atividades práticas com fins produtivos e imediatos, ou seja, a prática instrumental) passe a merecer maior atenção em nossos currículos de licenciaturas, na perspectiva da sua articulação com as teorias desenvolvidas. Esta é hoje uma tendência forte no Brasil, perceptível nas recomendações legais, como a nova Lei de Diretrizes e Bases - LDB (Lei n. 9.394/ 96), que em seu art. 65, estabelece 300 horas de prática de ensino nas licenciaturas. Ela também se faz presente nas recentes reformas curriculares na Europa Ocidental. Algumas dessas experiências propõem que a prática deve ser entendida como o eixo central do currículo de formação de professores.

Contudo, tenho a preocupação de que, no Brasil, esta tendência poderá levar não à referida articulação, mas ao entendimento segundo o qual promover o contato dos alunos das licenciaturas com as práticas sociais que ocorrem nas escolas seja o suficiente para dar o caráter mais "prático" à formação. Assim, o aumento de "horas práticas", entendido e realizado desta maneira, poderá conduzir ao praticismo ao empobrecimento teórico da formação. Isto pode ocorrer porque as práticas pedagógicas (tanto no sentido instrumental como no sentido de práticas sociais) não são suficientemente refletidas e teorizadas.

Um dos elementos necessários, embora não suficiente, para se superar esse entendimento na formação de professores, seria retomar o conceito de prática e de sua articulação com a teoria'. Para isso, torna-se necessário problematizar o concei-

I É somente por um exercício de liberdade semântica que eu utilizo aqui o termo formação de professores ou formação de educadores. Tal conceito supõe que se possa formar o professor, como resultado de ações externas e alterativas (originárias de um outro). Na compreensão teórica que fundamenta este estudo, baseada na pedagogia humanista, a formação de um 
to segundo o qual a prática seria o fundamento, critério de verdade e finalidade da teoria, tão forte ainda na pedagogia política do país. Tal conceito tem levado, possivelmente por uma leitura pouco relativizada de Marx, à subordinação da teoria e da reflexão à prática, o que dificulta a possibilidade desta prática converter-se em práxis. De certa forma, este conceito "aprisiona" a teoria, bem como a reflexão, que são atividades distintas. Compreender desse modo a relação entre teoria e prática é derivar de uma concepção filosófica que afirma a primazia da prática sobre a consciência e a reflexão, e também sobre a teoria, segundo o conhecido conceito de determinação em última instância.

Esse conceito marxiano afirma que, apesar da mútua influência entre a realidade concreta e a consciência do sujeito, em última instância é esta realidade que determina a consciência, isto é, tem maior peso na relação. Tal entendimento compromete parcialmente a potencialidade dialética do marxismo, pois a dialética pressupõe exatamente a mútua influência entre o mundo e a consciência, o interior e o exterior, em que cada dimensão tem uma força variável de caso a caso, impossível de determinar a priori. A necessidade de superar os impasses do problemático conceito de determinação em última instânciatem gerado brilhantes construções teóricas neomarxistas ao longo do século $X X$, como a teoria crítica.

Devido a esses problemas, a articulação teoria-prática precisaria ser realizada de outra forma, sem reduzir a teoria à prática, pois isso limita o desenvolvimento teórico e, conseqüentemente, uma das possibilidades de ampliação da prática. Para retomar esta relação entre teoria e prática, torna-se necessária uma reflexão que consiga estabelecer efetivamente uma dialética entre ambas. Assim se poderia entender que esses são elementos diferentes, mas que um não está "contido" no outro, e nem pode ser o seu limite, pois se assim fosse, não existiriam utopias. Um interessante conceito de articulação teoria-prática é aquele expresso por Adorno, que em uma leitura mais relativizada do pensamento marxiano, tenta mostrar como a teoria não pode estar desligada da prática, mas também não pode estar submetida a ela:

professor, como qualquer processo de formação humana, é mais complexa, embora também necessite de elementos e ações que são externas ao sujeito, e não estão presentes no seu repertório inicial: se assim fosse, o professor se formaria sozinho, sem necessitar da interação com outros sujeitos e objetos, o que, parece claro, não ocorre. Assim, quando me refiro ao termo formação de educadores, ou ao processo mais simples de formação de professores, estou utilizando este conceito de forma complexa, como um fenômeno que é, simultaneamente, auto, inter e alter formação. 
Se teoria e prática não são nem imediatamente o mesmo, nem absolutamente distintas, então sua relação é de descontinuidade. Não há uma senda contínua que conduza da prática à teoria (...) a teoria pertence ao contexto geral da sociedade e é, ao mesmo tempo, autônoma. Apesar disto, nem a prática transcorre independentemente da teoria, nem esta é independente daquela. Se a prática fosse o critério da teoria, (...) não poderia alcançar o que pretende; se a prática se regesse simplesmente pelas indicações da teoria, endurecer-se-ia doutrinariamente e, além disto, falsearia a teoria. $\bigcirc$ dogma da unidade entre teoria e prática é, em oposição à doutrina a que se reporta, adialético: ele capta simples identidade ali onde só a contradição tem chance de ser frutífera. (Adorno, 1995, p.227)

A forçada submissão da teoria e da reflexão à prática bloqueia tanto o potencial emancipatório da teoria, como a criatividade revolucionária da prática:

A exigência de unidade entre teoria e prática tem degradado a teoria a um papel servil, eliminando nesta aquilo que deveria trazer para a unidade. A perspectiva prática que se exige de toda teoria se converteu em um instrumento de censura. Quando o par teoria-prática perdeu a teoria, a prática se tornou irracional e integrou a própria política que pretendia superar, ou seja, ficou à mercê do poder. (Adorno, apud Giroux 1986, p.37-38)

No campo de teorização mais especificamente pedagógica, o conceito de prática pode ser tomado, por exemplo, nos autores do chamado paradigma da prática reflexiva, que apoiados nas reflexões da teoria crítica, concebem uma prática que pode ser constantemente reconhecida, refletida e modificada pelos agentes educacionais (Schöm, 1995; Pérez Gómez, 1995; Zeichner, 1995).

Esses autores entendem que, desta forma, é possível superar o enfoque racionalista e positivista de teoria e de prática, no qual a primeira tem sempre a primazia, e define, cientificamente, as diretrizes e técnicas que devem ser "aplicadas" à prática. Assim, o paradigma da prática reflexiva entende a prática mais como um processo de investigação contínua que um contexto de aplicação da teoria. Isso constitui um processo de investigação na ação, que articula teoria, prática e reflexão e impede que a ênfase na prática conduza à reprodução acrítica de esquemas e rotinas. Estes, que caracterizam tão bem a escolarização tradicional, transformam as práticas em procedimentos formais, burocráticos, cristalizados e pouco criativos.

Segundo essa visão, uma das principais causas dos problemas no trato com as questões da prática na formação de professores deriva da influência e dos pressupostos que o paradigma da racionalidade técnica ainda exerce em muitas universidades no mundo. Com visível influência humanista nas suas concepções de sujeito 
e de prática, mas principalmente respaldados nos filósofos da teoria crítica, alguns autores, especialmente Habermas, mostram como a racionalidade técnica nos orienta a ver a prática como um momento de aplicação dos princípios, técnicas e normas derivados da ciência, sendo, portanto, terminal e subsidiária em relação à teoria científica. O próprio fato de o practicum (momentos estruturados da prática pedagógica: aula prática, estágio, tirocínio) ser ministrado no fim dos cursos indicaria o caráter secundário e aplicado da prática. Ao contrário, os autores propõem que os cursos de formação de professores estejam centrados no practicum, que pode, inclusive, estar no começo dos cursos.

Um dos grandes problemas das posições que defendem a prática na formação de educadores é que freqüentemente essas perspectivas resvalam para o desconhecimento da importância da teoria e da reflexão, o que não é o caso dos autores citados. Evita-se o academicismo, e incorre-se no ativismo ou praticismo, ou atitudes muito próximas, comprometendo a formação dos futuros professores e a sua competência docente. A prática não se deve transformar em uma fuga à teoria: não é este - substituir a teoria - o seu sentido em um curso de formação de professores.

Se não for efetivamente realizada a articulação teoria-prática-reflexão, a grande tendência é se reforçar o que ocorre em algumas experiências no ensino superior: o empobrecimento teórico da formação, em nome de "atividades práticas". Estas acabam substituindo as atividades teóricas, ao invés de se articularem com elas, desobrigando professores e alunos de enfrentarem as dificuldades de compreensão, de aprendizagem e de desenvolvimento, que assim são adiadas para momentos posteriores do curso ou simplesmente não são resolvidas. $\bigcirc$ problema é muito sério, pois fornece alguns dos melhores argumentos às posições acadêmicas racionalistas que combatem as propostas de formação centradas na prática.

Contudo, o exercício da prática na formação pedagógica, com uma sólida preparação teórica na área de conhecimento que se vai ensinar, é imprescindível para a formação docente. Para que isso ocorra de forma integrada, e não mediante uma justaposição de formações paralelas (disciplinas pedagógicas e disciplinas da área específica), a articulação teoria-prática-reflexão é necessária, pois só as atividades práticas, em contextos sociais concretos, permitem a atribuição de significados, processo fundamental para a aprendizagem de conceitos e princípios teóricos.

\section{A AUTONOMIA RELATIVA DA EDUCAÇÃO}

A discussão inicial sobre a relação entre teoria e prática permite-nos abordar com mais clareza um problema fundamental para construir uma educação democrá- 
tica: a relação entre a prática pedagógica e as estruturas sociais. Não parece haver dúvida, nas análises de diferentes orientações teóricas, que toda prática pedagógica está de alguma forma articulada à sociedade em que ocorre. Mas quanto à forma como se dá a articulação não há consenso teórico. Sem cair em posições ingênuas como acreditar que apenas mudando a escola mudaremos a sociedade, não é possível, contudo, continuar sustentando a posição inversa, pois a escola não é apenas o resultado das estruturas sociais e acreditar nisso eqüivale negar a força da subjetividade, arriscando cair em um determinismo que não parece confirmável pela realidade.

A escola e os sujeitos que nela convivem possuem sempre um potencial para a mudança, e são, em parte, autodetermináveis, isto é, possuem autonomia relativa. A escola é influenciada pelas dimensões econômica, política e cultural da sociedade, mas também influencia essas dimensões. Além de receber a influência dessas estruturas, a capacidade de autodeterminação da coletividade escolar é afetada por quatro fatores: o nível de conhecimentos dos integrantes da comunidade, o grau de consciência e organização coletiva, o desejo de mudança e as condições materiais disponíveis. Não existe escola sem pessoas: em parte, são elas que fazem a escola ser de uma forma ou de outra, ao aceitar, resistir ou modificar as diretrizes e políticas definidas para a instituição.

O que uma escola é sempre resulta dessa interação, nunca apenas das políticas e condições materiais. A compreensão interacionista da relação escola-sociedade, própria à pedagogia humanista, leva-nos a entender a escola em constante devir, potencialmente capaz de influenciar as estruturas sociais, e sendo por elas constituída. Essa compreensão teórica se aproxima da adotada pelo marxismo culturalista, como na teoria da resistência, e me parece ser a mais consistente forma de superar a tão discutida questão: a escola é capaz de modificar a sociedade, ou ela depende da mudança social para se converter em agência de transformação?

A visão interacionista da escola nos faz atentar para a importância dos profissionais da educação no sucesso ou fracasso dos estudantes, muito mais que supõem as pesquisas sociológicas de caráter estrutural. As diversas pesquisas orientadas pelo interacionismo simbólico, fortemente influenciado pela pedagogia humanista e pelo filosofia social de John Dewey, mostraram, a partir da década de 30 nos EUA, e depois na Europa, como os professores influem, às vezes de forma sutil, na formação de seus alunos. As interações de professores e crianças - fortemente influenciadas pelas representações e significados que os profissionais atribuem a seus alunos e aos jovens em geral - exercem um efeito muito intenso nos resultados das práticas. Esse fenômeno é agravado pelo fato que muitas vezes os profissionais não têm uma consciência muito clara da influência. 
Na verdade, há hoje uma tendência bastante forte na pesquisa pedagógica, nos países desenvolvidos, para que seja admitida a importância do profissional docente nos resultados dos processos escolares. Assim, tais enfoques analisam os agentes educacionais como objetos das condições socioeconômicas e políticas, mas também como sujeitos capazes de interação criativa e de definição de situações:

Essa nova posição de pesquisa permite descobrir, por exemplo, que os professores desempenham um papel mais importante do que, habitualmente, lhes é reconhecido nos mecanismos de seleção e exclusão. (...) ○ ator não só deixa de ser manipulado pela forças que o superam, mas é capaz de fazer seus julgamentos e é preponderante o seu papel na estruturação do contexto. (Coulon, 1995, p.92)

Essas abordagens ressaltam a importância que a ação dos profissionais da escola, seu pensamento e sua formação têm nos resultados das práticas pedagógicas. Tal importância é analisada em conjunto com as questões estruturais, políticas e culturais, e não em oposição a elas. $\bigcirc$ enfoque tem sido largamente utilizado nos programas de inovação do ensino básico nos últimos anos, nos países desenvolvidos que têm buscado com mais empenho a melhoria e a democratização de seus sistemas de ensino, como os EUA, Reino Unido, Austrália e Europa Continental (Pérez Gómes, 1995; Zeichner, 1995; Coulon, 1995).

Essa concepção interacionista da escola se apóia em uma concepção de sujeito que busca superar uma visão determinista de ser humano, sem cair em perspectivas idealistas. Segundo Coulon (1995), até recentemente os sociólogos tinham supersocializado o comportamento dos atores sociais, deixando sem explicação como se dá, efetivamente, a interiorização das normas, o que conduz a uma visão segundo a qual o indivíduo age de forma automática e impensada, reproduzindo de modo não-interpretativo as normas e regras sociais. Assim, o ator social é visto como um "....idiota cultural que produz a estabilidade da sociedade ao agir em conformidade com alternativas de ação preestabelecidas e legítimas que the são fornecidas pela cultura" (Garfinkel, apud Coulon, 1995, p. 19).

Ao contrário, essas abordagens interacionistas defendem a existência de um imenso campo de contingências entre a regra, instrução ou norma social e sua aplicação pelo ator, pois a prática nunca é pura aplicação ou imitação de modelos preestabelecidos. Por conseqüência, o ator interpreta sua cultura e o seu mundo e dá significado às suas ações. Desse modo abre-se um campo de análise que nos permite considerar o ator social como, no mínimo, co-responsável pelas suas atitudes e ações cotidianas, incluindo as mudanças que o seu contexto e situação possibilitam. 
Da mesma forma, prossegue Coulon, o ator também interpreta as suas interações com os outros atores, agindo sobre elas - e as interações sociais são importantes para a definição de suas ações. Tais interpretações, contudo, não são definitivas, mas sofrem reinterpretações posteriores, de tal modo que as significações atribuídas às ações, e portanto, as próprias ações, podem ser modificadas pelo sujeito. $\bigcirc$ autor destaca que as abordagens sociológicas de caráter interacionista contribuem para realizar a síntese entre os níveis micro e macrossocial:

O modelo de ator é diferente e a relação entre a sua consciência e a interação é reflexiva: o ator é socializado pela interação, que por sua vez é gerada pelo ator. Por conseguinte, a estrutura e a ordem social não existem independentemente dos indivíduos que as constroem. Em compensação, as instituições influenciam o seu comportamento microssocial. (Coulon, 1995, p.35)

As sociologias de caráter interacionista, ao tentar superar as oposições rígidas entre indivíduo e estrutura, sofreram influência da filosofia social dos autores da Escola de Chicago, como John Dewey e George Mead. Mas uma outra poderosa influência contribuiu para esta visão de sujeito e de sociedade: a fenomenologia existencial européia. Essa concepção de sujeito aparece de forma muito clara no pensamento político de autores como Merleau-Ponty:

O social, como o próprio homem, tem dois pólos ou duas faces: é significante, podese compreendê-lo de dentro, e, ao mesmo tempo, a intenção pessoal encontra-se nele generalizada, amortecida, tende para o processo (...) a regulação que circunscreve o indivíduo não o suprime. Não há mais que escolher entre o individual e o coletivo. (...) Concebendo o social como simbolismo, conseguimos encontrar o meio para respeitar a realidade do indivíduo, a do social e a variedade das culturas sem torná-las impermeáveis umas às outras. O maior interesse desta nova investigação consiste em substituir as antinomias por relações de complementaridade. (MerleauPonty, 1980, p.275)

Não há aqui neste estudo nenhuma recusa em aceitar a força que as estruturas sociais exercem sobre a escola, definindo, em parte, o seu destino. Contudo, aqueles que negam o poder da educação, parece-me, caem em grande contradição. Eles afirmam que a escolarização, nas sociedades capitalistas, exerce um poderoso efeito de controle social e de reprodução das estruturas existentes, favorecendo a formação de subjetividades conformadas e adaptadas ao status quo. As práticas pedagógicas teriam, segundo esta concepção, limites muito estritos como meio de transformação social. 
Mas existe no argumento uma contradição bastante acentuada, demonstrada por um simples exercício de lógica. Se a educação escolar não é capaz de favorecer a mudança social pela formação de diferentes subjetividades, por que então os grupos dominantes são tão cuidadosos na contenção da qualidade da escola pública? Ao mesmo tempo que esta concepção aceita o papel conservador da educação, rejeita as possibilidades democráticas mais radicais da escola, mesmo se esta fosse estruturada em padrões divergentes.

Se o processo escolar tem força para padronizar e formatar nos atuais modelos, por que não teria força para liberar, potencializar, expandir, se fosse proposto em bases diferentes? A força dos processos educativos só funciona no sentido negativo? Para onde irá este poder, aceito pelos próprios autores, se a escola estruturarse de outra maneira? Onde há uma negatividade, deve haver uma positividade subjacente. Esta discussão não é uma mera especulação teórica, pois as concepções restritivas sobre a educação, no senso comum e na teoria, exercem forte influência sobre a ação dos agentes educacionais.

Não somente a lógica mostra esta contradição. Há também evidências práticas, demonstrando que as possibilidades democráticas da educação não são resultado de um ingênuo otimismo pedagógico, tampouco produto de fantasias humanistas. Vejamos três destas evidências. Elas aparecem quando nos colocamos numa situação prática, que já ocorreu inúmeras vezes nas escolas. Imaginemos uma escola com uma proposta avançada de formação, tentando trabalhar com as crianças valores, atitudes e interesses alternativos, aqueles que são predominantes em nossa sociedade, como colaboração, solidariedade e autonomia política. Contudo, a família de certa criança defende valores e costumes completamente diferentes destes, até mesmo antagônicos. Teria esta formação escolar condição de competir com a influência familiar?

A primeira evidência da força da escola vem do fato que, cada vez mais, as crianças estão entrando mais cedo nela. Isso tem ocorrido mais intensamente no Brasil, para as camadas mais pobres da população, a partir de 1996, quando a nova LDB regulamentou o preceito constitucional, de 1988, que garante o direito de toda criança à educação infantil, na faixa de 0 a 6 anos. Embora esse direito ainda esteja sendo conquistado na prática, com muita pressão popular, o ingresso precoce na escola reforça o poder de influência da escola em relação à família.

A segunda evidência prática vem do próprio incômodo que a escolarização, muitas vezes, causa nas famílias de valores diferentes daqueles professados pela escola. $\bigcirc$ incômodo por vezes é tão intenso que os pais tiram a criança daquela escola, conforme tive oportunidade de acompanhar várias vezes quando era pro- 
fessor do ensino básico. Se os valores da escola não possuíssem força e não incomodassem, por que tirar a criança do ambiente escolar? Não bastaria deixar que esta influência fosse anulada pela formação familiar?

A terceira evidência, algo que precisa ser mais explorado pelas escolas democráticas, é percebida quando os pais são incluídos na elaboração do projeto educativo da escola. Muitos desses pais sentem-se valorizados e modificam suas idéias no contato com os educadores, abandonando suas desconfianças em relação a práticas alternativas e aderindo a elas quando percebem que, bem estruturadas, não constituem um experimentalismo irresponsável com seus filhos. Esse processo de incluir os pais na elaboração do projeto educativo da escola mostra que eles podem influenciar a escola, mas a escola também pode influenciar os pais, aumentando o raio de sua ação democrática e comunitária.

É importante ressaltar que uma das resistências a esta inclusão dos pais e da comunidade na elaboração e no acompanhamento do projeto da escola não vem do Estado "todo-poderoso", nem da onipresente classe dominante, como acreditam alguns autores. Uma das mais fortes resistências muitas vezes vem dos próprios profissionais da escola, que consideram tal prática uma intromissão no seu trabalho. É uma resistência gerada por um fator subjetivo, portanto.

\section{A EDUCAÇÃO DEMOCRÁTICA}

Apesar das críticas que recebe, a chamada pedagogia tradicional ainda desperta em alguns uma esperança de redenção, decorrente da suposta possibilidade de construção de uma educação democrática a partir das práticas tradicionais. Estas teriam, segundo alguns autores, elementos positivos e uma estrutura de "transmissão" do conhecimento que seria válida. Contudo, parece-me uma grande contradição.

Se propomos explicitamente o resgate do saber escolar instituído e (implicitamente) o resgate da própria prática dominante, esquecemos que esta prática não é dominante por acaso, mas exatamente por ser adequada a um projeto político em vigor, que é excludente. Assim, não há como fundamentar uma educação democrática sem uma crítica radical ao modelo predominante. Se buscamos esta fundamentação no próprio modelo existente, caímos em uma contradição insuperável entre fins declarados e meios sugeridos.

Exatamente por essas contradições, não parece possível a construção de uma educação democrática com base nos métodos fortemente centrados no professor e no currículo predefinido. A chamada educação tradicional (na verdade, práticas tradicionais), tão presente ainda em nossas escolas, não é e jamais será democráti- 
ca, pois os seus fundamentos filosóficos e o seu método são antiparticipativos e excessivamente centralizadores - portanto, antidemocráticos na essência. Como produzir uma sociedade democrática, vivendo práticas não democráticas? Essa contradição mostra a inviabilidade das práticas tradicionais e de seus princípios estruturantes se converterem em experiências favoráveis à vida democrática.

Como contribuir na formação de sujeitos democráticos se o processo não é democrático? Os alunos sentem a prática pedagógica no seu campo emocional e no próprio corpo, e não apenas no campo cognitivo, porque estas dimensões são indissociáveis. Se é correto que a democratização da relação pedagógica não é condição suficiente para a democratização social, ela é, contudo, condição essencial para a estruturação de uma subjetividade autônoma, pois processos autoritários não conseguem servir de base para resultados democráticos. Desta forma, parece que o problema é sim, embora apenas parcialmente, de definir relações democráticas no interior da escola.

Incorremos freqüentemente em grande equívoco se pensamos que a prática pedagógica não poderia ser democrática já no seu ponto de partida, pois democracia significa (supõe-se) condições de igualdade entre os agentes, e o professor e o aluno são desiguais. Contudo, democracia não significa que todas as condições sejam iguais entre os agentes, pois isto levaria a uma uniformização que não existe nem nas comunidades mais igualitárias. O que caracteriza a democracia real é a garantia de condições básicas a todos (alimentação, moradia, trabalho, cultura etc.), a inexistência de qualquer tipo de exploração e o exercício de relações onde haja liberdade e também limites. A autoridade, em contextos efetivamente democráticos, passa a ser definida pela função, necessidade e experiência, e trabalha com limites freqüentemente sujeitos à negociação e jamais arbitrários.

Essa relação democrática não impede a influência do mais experiente sobre o imaturo, aliás a diferença entre professores e alunos é imprescindível para que se dê o ato educativo, ela constitui este ato, pertence à sua estrutura. $\bigcirc$ problema é a natureza desta diferença, e comose dará esta intervenção: uma relação democrática, na concepção da pedagogia humanista, dosa a influência de acordo com as necessidades de aprendizagem e desenvolvimento da criança. Ela desafia, estimula e orienta, mas não constrange. Seu princípio de atuação nunca é ideológico (no sentido de falsa consciência), isto é, esta interferência tem suas motivações explícitas negociadas sempre que necessário. Por isso, ela não esconde nunca em seu bojo outros interesses, como dominar ou manipular aquele que se pretende educar.

Dentro da concepção democrática da relação, entendemos que as crianças não são refratárias aos processos que estimulam o seu crescimento, desde que per- 
cebam a conexão destes processos e o seu desenvolvimento. Se há reações muito fortes por parte da criança à interferência do adulto e à prática pedagógica, provavelmente o processo está permeado por elementos arbitrários e impositivos. $\bigcirc$ professor, muitas vezes, não percebe o caráter coercitivo desses elementos e como eles constrangem a estruturação da autonomia da criança, ferindo o próprio conceito de emancipação. Ao menos parcialmente, as crianças têm consciência de suas necessidades de crescimento e das demandas do mundo adulto. Mas elas precisam de um ambiente propício para conseguir articular tais necessidades com o que há de válido no currículo escolar.

Assim, questionar a centralidade do papel do professor nos paradigmas convencionais não significa, de modo algum, tornar secundária a importância desse profissional. Ao contrário, o que ocorre é que se modifica o tipo de interação que ele produz junto com as crianças, pois o seu papel é ressignificado. $\bigcirc$ desenvolvimento da consciência crítica depende da participação em experiências e relações em que haja autonomia na prática, e não apenas no tratamento do conteúdo e na teoria. Caso contrário, o grande risco é permanecer na abstração.

Essas reflexões se apóiam no conceito democrático de vida social. Se acreditamos que esta é a forma mais válida de viver em comunidade, torna-se urgente definir com clareza o que se entende por democracia. Tal conceito, neste texto, refere-se a uma proposta radical de democracia, diferente do modelo liberal vigente. Pode surgir a partir dele, pela participação ampliada dos sujeitos e coletividades nos processos de decisão e nas riquezas produzidas, mas não se reduz a esse modelo.

No século $X X$, um dos autores que trabalhou um conceito radical de democracia foi John Dewey. Suas reflexões servem de base, ainda hoje, para teorias do pensamento social avançado, como a teoria da resistência. Para Dewey², democracia não é apenas uma forma de governo, mas uma forma de vida, aquela que permite as mais plenas e realizadoras experiências para todas as pessoas (Dewey, 1970, 1979, 1979a).

Tal forma de vida social não pode existir sem ampla participação popular e sem o debate livre e aberto de opiniões. Sua base subjetiva é o ambiente de cooperação e solidariedade entre as pessoas. Para sua realização é imprescindível, no

2 O pensamento pedagógico de Dewey, como o de outros autores da Escola Nova, representou uma fundamental contribuição à luta pela democratização da educação, algo pelo qual nós lutamos ainda hoje. Contudo, seus livros estão todos esgotados, e não são reeditados no Brasil há vários anos. O mercado editorial prestaria um grande serviço à educação democrática no país e à formação de educadores, se reeditasse algumas obras de Dewey, principal- 
plano material, uma mudança radical na economia, que deve ser controlada pela sociedade, a qual precisa impor-Ihe os limites necessários para que ela exista em razão da realização coletiva, e não o contrário. Dewey não fundamenta o conceito de democracia em princípios abstratos, mas na qualidade da experiência vivida. Isso afasta suas reflexões dos conceitos do liberalismo conservador, pois liberdade e igualdade precisam ser vividas na experiência em uma sociedade efetivamente democrática:

Seria possível achar-se qualquer razão (para fundamentar a democracia) que não fosse reduzir-se à crença de que o arranjo social democrático promove melhor qualidade da experiência humana - experiências mais largamente acessíveis e mais capazes de satisfazer amplos anseios humanos do que as formas não-democráticas e antidemocráticas de vida social? O princípio de respeito à liberdade individual e à decência e amabilidade nas relações humanas não resulta afinal da convicção de que tais coisas decorrem da qualidade mais alta da experiência e por parte do número maior de pessoas, qualidade que falta aos métodos de repressão, coerção ou força? A razão de nossa preferência não é a de acreditarmos que a consulta mútua e as convicções alcançadas pela persuasão tornam possível, em larga escala, melhor qualidade da experiência do que a que se pode obter por qualquer outro método? (Dewey, 1979a, p.25)

Ao definir a democracia em uma perspectiva experiencial e pragmática, Dewey supera o conceito exclusivamente formal e abstrato de democracia. Essa maneira formal de definir democracia, como está hoje tomada de modo acentuadamente ideológico no discurso neoliberal, acaba por produzir resultados não democráticos. Isso ocorre porque ela reforça a crença segundo a qual sociedade democrática é aquela em que existem leis que prescrevem os direitos básicos, embora as condições sociais não garantam a experiência do usufruto de tais direitos por todas as pessoas. Dewey rejeita qualquer definição metafísica de democracia, bem como de liberdade:

A liberdade não é apenas uma idéia ou um princípio abstrato. É poder, poder efetivo de fazer certas coisas. Não existe a liberdade em geral, isto é, em sentido amplo. Por isto, a liberdade é uma questão social, e não somente um direito do indivíduo particular, pois ela é relativa à distribuição dos poderes de ação em um

mente agora que o seu pensamento está sendo redescoberto e rediscutido com intensidade. Pelo menos duas obras suas, pequenas, de leitura acessível e que provavelmente teriam bastante procura: Experiência e educação e Vida e educação, esta última com uma excelente e didática introdução de Anísio Teixeira ao pensamento de Dewey (Dewey, 1979, 1979a). 
dado momento. Quando há liberdade em um lugar, há restrição em outros: aquilo que uma pessoa pode fazer está em relação com o que as outras podem ou não fazer. A luta pela liberdade é importante devido às suas conseqüências na produção de relações eqüitativas, justas e humanas entre homens, mulheres e crianças. (Dewey, 1952, p.72, 101)

Profundamente influenciados pela pedagogia humanista e pelo pensamento democrático de John Dewey, alguns autores norte-americanos da teoria da resistência, como Henry Giroux e Michael Apple, têm buscado, nos últimos anos, fundamentar teoricamente o conceito de escolas democráticas. Por tal conceito, que tem orientado experiências práticas nos EUA, entende-se aquelas escolas que têm por preocupação central ampliar, por meio da educação, as condições favoráveis ao modo de vida democrático. Segundo Dewey, para se assegurar e manter a vida democrática, é preciso que as pessoas tenham a oportunidade de descobrir o que ela significa, e como pode ser vivenciada na prática (Dewey, 1979).

As condições favoráveis a este modo de vida, que podem ser trabalhadas pelas escolas democráticas, segundo Apple e Beane (1997), são o livre fluxo de idéias, que permite às pessoas estarem tão bem informadas quanto possível; fé na capacidade individual e coletiva das pessoas criarem condições de resolver problemas; o uso da reflexão crítica para avaliar problemas, idéias e políticas; preocupação com o bemestar dos outros, com o bem comum e com a dignidade e os direitos dos indivíduos e minorias; compreensão de que a democracia não é um "ideal" a ser buscado, mas um conjunto de valores que devemos viver na prática e que deve regular a nossa vida coletiva; e a organização de instituições sociais para promover o modo de vida democrático.

Como se vê, esta definição de educação democrática tem, ao lado das preocupações políticas mais amplas, também uma preocupação existencial e prática. Ou seja, este tipo de educação precisa ser vivido nas próprias relações pedagógicas, e não apenas no caráter social dos conteúdos trabalhados pela escola. Por isso, a relação com os educadores e demais profissionais da escola tem neste caso uma fundamental importância na formação democrática da criança e do jovem. Contradições entre o discurso, a prática e as atitudes dos profissionais provocam um efeito devastador na estruturação da autonomia das crianças.

Dessa forma, a competência dos educadores para trabalhar os modelos democráticos de educação é um dos mais graves e delicados problemas na área. $E$ isso nos conduz à questão da formação profissional, à formação docente, que é um dos pontos mais críticos para a estruturação de uma educação democrática. Ela 
precisa apoiar-se em critérios relativos ao desenvolvimento de competências favoráveis ao trabalho democrático.

Juntamente com outros profissionais, defendo que a formação se baseie em competências e não apenas em saberes. A escolha se deve a quatro motivos. $\bigcirc$ primeiro é que competências é um conceito mais amplo que saberes. Competência é a faculdade de mobilizar saberes, habilidades, técnicas e experiências prévias para solucionar, com sucesso e eficácia, situações problemáticas, geralmente em contextos sociais práticos e definidos.

O ressurgimento do conceito de competências e sua importância na formação escolar deve muito, atualmente, ao trabalho intelectual de autores como o sociólogo suíço Philippe Perrenoud. Contudo, a luta para que a educação não se baseie somente na difusão de conteúdos e consiga desenvolver mais integralmente o sujeito é uma muito antiga, e tem na Escola Nova a sua mais potente tendência. Já em 1916, em Democracia e educação, Dewey defendia que é grande avanço pensar e praticar educação objetivando o desenvolvimento de habilidades e competências, superando o enfoque centrado nos conteúdos. Neste caso, os saberes científicos passam a ser os meios de desenvolver competências e não um fim em si mesmo.

A segunda vantagem de trabalhar a formação centrando-se em competências é que elas têm, pela sua definição, um caráter prático e social. Sem desprezar o conhecimento científico, esse tipo de formação procura ajudar o sujeito que aprende a utilizar os saberes em situações operativas e existenciais. Isso se dá sempre em contextos sociais, pois nós dificilmente vivemos situações completamente individuais, característica que permite superar, se for bem trabalhada, o ensino academicista e livresco, que tanto afasta os alunos (especialmente das classes populares) do saber elaborado.

A terceira vantagem é que as competências permitem à educação trabalhar com situações e desafios complexos, mais próximos de situações reais, que serão enfrentadas pelo educando. As situações sociais reais têm um alto grau de complexidade e instabilidade, que a formação baseada em conteúdos e saberes não consegue reproduzir, nem parcialmente.

A quarta vantagem em tomar as competências como base da formação é que elas, se trabalhadas criticamente, permitem ao educando desenvolver a reflexão crítica continuamente. Elas permitem, por um lado, o exercício das capacidades intelectuais com vistas ao agir produtivo, isto é, a competência para atuar de forma consistente no mundo do trabalho, o que eu considero necessário por razões práticas.

Mas se trabalhadas de forma crítica e reflexiva, as capacidades intelectuais do educando permitem também a sua inserção social crítica, a consciência dos proble- 
mas que se levantam contra a sua cidadania, a constante atitude de questionamento e reflexão sobre os fins daquilo que está fazendo. Assim, capacidade de produzir e capacidade de perceber amplamente são desenvolvidas em paralelo, impedindo que as habilidades intelectuais se reduzam à mera capacidade do pensar instrumental, que transforma o trabalhador em uma mão-de-obra produtiva e dócil, com o mínimo de subjetividade ativa.

Alguns argumentam que o trabalho com competências permitiria que a formação dos jovens se reduzisse apenas ao pensar instrumental, não crítico; o que é verdade, isso pode ocorrer com qualquer tipo de formação, inclusive com aquela baseada em conteúdos. Assim, o risco não é inerente ao trabalho com competências, mas depende de como estas são desenvolvidas na formação, e com que fins.

Apresentadas estas questões sobre a formação, tentarei descrever as competências docentes que poderiam, a meu ver, orientar a formação de professores para uma educação democrática. Creio que as competências precisam contemplar cinco áreas, o que não significa uma amplitude excessiva, pois como aqui é considerada, essa amplitude se inscreve no campo de identidade da prática educativa, isto é, no binômio aprendizagem-desenvolvimento. As cinco competências seriam:

a. Competência de conteúdos. domínio do saber geral e curricular, e a capacidade de promover um processo de transposição didática.

b. Competência pedagógica: capacidade de mobilizar os conhecimentos teóricos aprendidos das teorias pedagógicas para compreender e resolver situações reais em sala de aula. Esses conhecimentos geralmente aprendidos durante a formação, como as concepções sobre a aprendizagem e desenvolvimento, ou as teorias sociológicas sobre a relação escola-sociedade, são utilizados pelo educador indiretamente e, poucas vezes, diretamente nas situações pedagógicas reais.

c. Competência metodológica: inclui tanto a habilidade de ensinar e se comunicar com clareza (didaktiké) como a capacidade de perceber como cada grupo de alunos aprende, e organizar as situações mais propícias a estas aprendizagens; isto depende da capacidade de planejar, mas esta pode não estar associada, em uma pessoa, à habilidade de ensinar: pode ocorrer uma habilidade sem a outra, o que mostra a complexidade deste campo de competência.

d. Competência relacional e ética: capacidade de estimular relações interpessoais construtivas, criando um clima socioemocional favorável à aprendi- 
zagem, ao desenvolvimento e à expressão crítica; essas habilidades exigem do educador uma estrutura emocional razoavelmente equilibrada e dinâmica, a qual se revela na capacidade de lidar com os aspectos emocionais da experiência pedagógica; esse aspecto da competência depende acentuadamente da relação afetiva do educador com sua profissão, pois envolve diretamente a sua dimensão subjetiva.

e. Competência crítica: ser capaz de colocar um discurso ou idéia em questão, pensando e percebendo com radicalidade e superando atitudes ingênuas ou superficiais diante do instituído; é essa capacidade de desvelamento do aparente e do hegemônico que permite ao profissional desmontar os discursos, idéias e relações sociais existentes, e demonstrar os valores e interesses que permeiam esses elementos, que freqüentemente não se revelam de imediato. Tal capacidade, contudo, não deve ser confundida com a simples adoção de uma opção político-partidária ou um determinado referencial teórico, pois esses não garantem, por si mesmos, o desenvolvimento da atitude crítica.

\section{REFERÊNCIAS BIBLIOGRÁFICAS}

ADORNO, T. Palavras e sinais. modelos críticos 2. Petrópolis: Vozes, 1995.

ADORNO, T.; HORKHEIMER, M. Dialética do esclarecimento: fragmentos filosóficos. Rio de Janeiro: Zahar, 1985.

APPLE, M. Educação e poder. Porto Alegre: Artes Médicas, 1989.

APPLE, M.; BEANE, J. Escolas democráticas. São Paulo: Cortez, 1997.

COULON, A. Etnometodologia e educação. Petrópolis: Vozes, 1995.

DEWEY, J. Como pensamos. como se relaciona o pensamento reflexivo com o processo educativo: uma reexposição. São Paulo: Nacional, 1959.

A Criança e o programa escolar. São Paulo: Abril Cultural, 1980. (Coleção

Os Pensadores)

Democracia e educação: introdução à filosofia da educação. São Paulo:

Nacional, 1979.

Experiência e educação. São Paulo: Nacional, 1979a.

Interesse e esforço. São Paulo: Abril Cultural, 1980a. (Coleção Os Pensa-

dores) 
. El Hombre y sus problemas. Buenos Aires: Editorial Paidós, 1952.

. Liberalismo, liberdade e cultura. São Paulo: Nacional, 1970.

Pode a educação participar na reconstrução social? Currículos sem Fronteiras, v. I, n. 2, p. I89-193, jul./dez. 2001.

Reconstrução em filosofia. São Paulo: Nacional, 1958.

GIROUX, H. Praticando estudos culturais nas faculdades de educação. In: SILVA, T. (org.). Alienigenas na sala de aula: uma introdução aos estudos culturais em educação. Petrópolis: Vozes, 1995, p.85-103.

Professores como intelectuais. rumo a uma pedagogia crítica da aprendizagem. Porto Alegre: Artes Médicas, 1997.

Teoria critica e resistência em educação: para além das teorias da reprodução. Petrópolis: Vozes, 1986.

GOODSON, I. Currículo: teoria e história. Petrópolis: Vozes, 1995.

MERLEAU-PONTY, M. De Mauss a Claude Levi-Strauss. São Paulo: Abril Cultural, 1980. (Coleção Os Pensadores)

MOGILKA, M. Autonomia e formação humana em situações pedagógicas: um difíicil percurso. Educação e Pesquisa. São Paulo: USP, n. 2, p.57-68, dez. 1999.

A Pedagogia da experiência e sua importância em uma educação democrática. Educação em Revista. Belo Horizonte: UFMG, n. 32, p.85-I02, dez. 2000.

NÓVOA, A. Os Professores e sua formação. Lisboa: Dom Quixote, 1995.

PÉREZ GÓMES, A. O Pensamento prático do professor: a formação do professor como profissional reflexivo. In: NÓVOA, A. Os Professores e sua formação. Lisboa: Dom Quixote, 1995. p.93-1|4.

SCHÖM, D. Formando professores reflexivos. In: NÓVOA, A. Os Professores e sua formação. Lisboa, 1995. p.77-91.

ZEICHNER, K. Novos caminhos para o practicum: uma perspectiva para os anos 90. In: NÓVOA, A. Os Professores e a sua formação. Lisboa: Dom Quixote, 1995. p. I I 5- 138.

Recebido em: abril 200 I

Aprovado para publicação em: outubro 2002 